1 Mortimer PP. Hypothesis: the aplastic crisis of hereditary spherocytosis is due to a single transmissible agent. 7 Clin Pathol 1983;36:445-8.

2 Serjeant GR, Mason K, Topley JM, et al. Outbreak of aplastic crises in sickle cell anaemia associated with parvovirus-like agent. Lancet 1981;ii:595-7.

Pattison JR, Jones SE, Hodgson J, et al. Parvovirus infections and hypoplastic crisis in sickle-cel anaemia. Lancet $1981 ;$ i:664-5.

4 Kelleher JF, Luban NLC, Mortimer PP, Kamimura T. Human serum "parvovirus": a specific cause of aplastic crisis in children with hereditary spherocytosis. F Pediatr 1983;102:720-2.

5 Lefrere JJ, Courouce A-M, Girot R, Bertrand Y, Soulier J-P. Six cases of hereditary spherocytosis revealed by human parvovirus infection. Br 7 Haematol 1986;62:653-8.

6 Shneerson JM, Mortimer PP, Vandervelde EM. Febrile illness due to a parvovirus. Br Med $\mathcal{f}$ 1980;280:1580.

7 Anderson MJ, Jones SE, Fisher-Hoch SP, et al. Human parvovirus, the cause of erythema infectiosum (fifth disease)? Lancet 1983; ; 1378 .
8 Cossart YE, Field AM, Cant B, Widdows D. Parvovirus-like particles in human sera. Lancet $1975 ; \mathrm{i}: 72-3$

9 Mortimer PP, Humphries RK, Moore JG, Purcell RH, Young NS. A human parvovirus-like virus inhibits haematopoietic colony formation in vitro. Nature 1983;302:426-9.

10 Young NS, Mortimer PP, Moore JG, Humphries RK. Characterisation of a virus that causes transient aplastic crisis. F Clin Invest 1984;73:224-30.

11 Anderson MJ, Davis LR, Hodgson J, et al. Occurrence of infection with a parvovirus-like agent in children with sickle cell anaemia during a two-year period. $\mathcal{f}$ Clin Pathol 1982;35:744-9.

12 Zeldis JB, Dienstag JL, Gale RP. Aplastic anaemia and non-A, non-B hepatitis. Am $\mathcal{F}$ Med 1983;74:64-8.

13 Lazarus KH, Baehner RL. Aplastic anaemia complicating infectious mononucleosis: a case repor and review of the literature. Pediatrics 1981;67:907-10.

14 Lewis SM, Gordon-Smith EC. Aplastic and dysplastic anaemias. In: Hardisty RM, Weatheral DJ, eds. Blood and its disorders. 2nd ed. Oxford: Blackwell Scientific Publications, 1982: $1229-68$

\title{
Normal pressure hydrocephalus
}

In 1965 Raymond Adams and his coworkers described a new clinical syndrome of dementia with psychomotor retardation, unsteadiness of gait, and urinary incontinence. It was of insidious onset and associated with a characteristic pneumoencephalographic appearance of ventricular enlargement with an absence of air over the cerebral cortex owing to subarachnoid obstruction but with normal pressure in the cerebrospinal fluid on lumbar puncture. Patients showed clinical improvement after cerebrospinal fluid shunt procedures. $^{12}$

From the beginning the aetiology and pathophysiology of the condition have been difficult to understand, and they are probably multifactorial. It has been described after head injury, ${ }^{2-5}$ subarachnoid haemorrhage, ${ }^{3-7}$ intracranial surgery, ${ }^{8}$ cerebrovascular disease, ${ }^{9-11}$ meningoencephalitis, ${ }^{1349}$ and in association with a brainstem glioma, ${ }^{12}$ third ventricular cyst, ${ }^{1}$ cerebellar haemangioblastoma, ${ }^{13}$ aqueduct stenosis, ${ }^{5}$ and third ventricular compression from an ectatic basilar artery. ${ }^{14}{ }^{15}$ In perhaps as many as half of all cases there is no obvious cause. The factor common to all of these conditions is impairment of outflow and resorption of cerebrospinal fluid; this leads to a rise of the intraventricular pressure, which diminishes as the ventricles distend. ${ }^{216} 17$ Neurological signs and symptoms are produced by a combination of mechanical stretching of periventricular fibre pathways, ${ }^{18}$ of parenchymal brain disturbance as a result of diminished cerebral blood flow and reduced metabolism, ${ }^{819-21}$ and of periventricular oedema from transependymal flow of cerebrospinal fluid. ${ }^{20-23}$ Cerebrospinal fluid diversion procedures, usually ventriculoatrial or ventriculoperitoneal shunts with valves which open at low pressures, have reversed these abnormalities and produced clinical improvement in some highly selected patients-as many as two thirds in some series. 3792431

It is, however, difficult on clinical grounds alone to select patients who will benefit from shunt procedures and to distinguish them from those with dementia due to irreversible causes such as Alzheimer's disease or multiple cerebral infarcts. Several investigations have been used. The first was pneumoencephalography with some specific diagnostic measures. ${ }^{123233}$ Computed tomography is now the preferred imaging method, ${ }^{34-36}$ and it may be combined with metrizamide cisternography. ${ }^{37-39}$ Investigations which determine the absorption and flow characteristics of cerebrospinal fluid have included radionuclide encephalography and cisternography, ${ }^{50-42}$ estimation of blood radionuclide concentrations, ${ }^{43}$ lumbar saline infusion tests, and monitoring of intracranial pressure. ${ }^{71314446}$ Despite or because of this multiplicity of tests there has not been general agreement about which factors best predict a successful outcome from shunting, either singly or in combination, and their prognostic value has been questioned. ${ }^{3723-252728303147}$

If surgery was free of risk it might be a reasonable proposition to carry out a cerebrospinal fluid diversionary procedure on any demented patient with ataxia and urinary incontinence and large ventricles on computed tomography. In practice, however, complications-shunt infection, subdural haematoma and effusion, epileptic seizures, and shunt malfunction-occur in about one third of patients (range $9 \%$ $44 \%),{ }^{3225273147}$ and such a policy would inevitably lead to operations being done on many patients with Alzheimer's disease and other irreversible brain degenerations and parenchymal damage who could not hope to improve. More recent studies of cerebral blood flow and metabolism have shown that the regional flow, volume, and metabolism are reduced in patients with normal pressure hydrocephalus, particularly in the frontal, temporal, and basal ganglia areas. If the ventricular pressure and size are reduced the clinical state improves and there has been an accompanying improvement in these factors in most but not all reports. ${ }^{202148.53}$ These techniques are not, however, sufficiently sensitive yet to differentiate reliably between normal pressure hydrocephalus and Alzheimer's disease and other forms of dementia.

Changes in Alzheimer's disease are detectable by positron emission tomography ${ }^{54}$ - decreased cortical blood flow and regional metabolism for glucose and oxygen in frontal, temporal, and parietal regions. A recent report by Jagust et $a l$, using positron emission tomography with labelled fluorodeoxyglucose to map cerebral glucose metabolism, showed global cerebral hypometabolism in three patients with normal pressure hydrocephalus; this could be distinguished from the bilateral temporoparietal hypometabolism seen in Alzheimer's disease. ${ }^{55}$ The apparent paradox of global metabolic disturbance in normal pressure hydrocephalus with positron emission tomography, whereas blood flow studies usually show focal reduction, has not been explained. Positron emission tomography is an expensive, technically complex, and time consuming technique, available in only a few centres world wide. Possibly metabolic analogues of positron emitters may be synthesised and labelled with $\gamma$ emitters to allow single photon tomographic studies to be undertaken-and this should be possible in most departments of nuclear medicine. Preliminary results in Alzheimer's disease are encouraging. ${ }^{56}$ Such studies are in a very early 
stage, and the numbers are small, so no definite conclusions can be drawn, but these provide some optimism for the future.

Meanwhile, while waiting for new diagnostic techniques to become available, and faced with demented patients who may have normal pressure hydrocephalus, how should the clinician select those likely to benefit from shunt procedures? Other remediable causes of dementia should be excluded. Surgery seems to give best results in patients showing the full clinical syndrome of dementia, disturbance of gait, and urinary incontinence, in whom the history is short and progressive, and in whom a clear cut aetiology has been established. Computed tomography scanning should be performed to exclude tumours, substantial infarction, and considerable generalised atrophy. The ventricles must be enlarged, and favourable features are lack of cortical atrophy and the presence of frontal white matter periventricular lucency. Whether to proceed to complementary investigations of cerebrospinal fluid dynamics and absorption of cerebral blood flow and metabolism will depend on the availability of resources and the experience of the doctor.

It is now 21 years since the clinical syndrome of normal pressure hydrocephalus was first described, yet there is no general agreement on its strict definition or how to select cases for treatment-which carries a substantial risk. With such diverse aetiologies we are probably dealing with more than one condition, and I do not believe that we know their natural histories. Most published studies have been retrospective, without controls. With a rapidly increasing population of patients with dementia I believe that the time is ripe for a strictly defined prospective controlled study of a large number of patients to answer these questions.

\section{MiLNE ANDERSON}

Consultant Neurologist,

Midland Centre for Neurosurgery and Neurology,

Smethwick

Warley,

West Midlands B67 7JX

1 Adams RD, Fisher CM, Hakim S, Ojemann RG, Sweet WH. Symptomatic occult hydrocephalus with "normal" cerebrospinal fluid pressure. A treatable syndrome. N Engl f Med 1965;273: 117-26.

2 Hakim S, Adams RD. The special clinical problem of symptomatic hydrocephalus with normal cerebrospinal fluid pressure. Observations on cerebrospinal fluid dynamics. I Neurol Sci 1965;2:307-27

3 Laws ER, Mokkri B. Occult hydrocephalus: results of shunting correlated with diagnostic tests. Clin Neurosurg 1977;24:316-33.

4 Hill ME, Lougheed WM, Barnett HJM. A treatable form of dementia due to normal pressure communicating hydrocephalus. Can Med Assoc $\mathcal{F}$ 1967;97:1309-20.

5 Ojemann RG, Fisher CM, Adams RD, Sweet WH, New PJF. Further experience with the syndrome of "normal" pressure hydrocephalus. J Neurosurg 1969;31:279-94.

6 Foltz EL, Ward AA. Communicating hydrocephalus from subarachnoid bleeding. I Neurosurg 1956;13:546-66.

7 Symon L, Hinzpeter T. The enigma of normal pressure hydrocephalus: tests to select patients for surgery and to predict shunt function. Clin Neurosurg 1977;24:285-315.

8 Greitz TVB, Grepe AOL, Kalmer MSC. Pre- and post-operative evaluation of cerebral blood flow in low pressure hydrocephalus. $\mathcal{F}$ Neurosurg 1969;31:644-51.

9 Udvarhelyi GB, Wood JH, James AE, Bartlet D. Results and complications in 55 shunted patients with normal pressure hydrocephalus. Surg Neurol 1975;3:271-5.

10 Earnest MP, Fahn S, Karp JH, Rowland LP. Normal pressure hydrocephalus and hypertensive cerebrovascular disease. Arch Neurol 1974;31:262-6.

11 Koto A, Rosenberg G, Zingesser LH, Horoupian D, Katzman R. Syndrome of normal pressure hydrocephalus: possible relationship to hypertensive and arterisclerotic vasculopathy. $\mathcal{F}$ Neurol Neurosurg Psychiatry 1977;40:73-9.

12 Messert B, Henke TK, Langheim W. Syndrome of akinetic mutism associated with obstructive hydrocephalus. Neurology 1966;16:635-49.

13 Moore MT. Progressive akinetic mutism in cerebellar haemangioblastoma with "normal" pressure hydrocephalus. Neurology 1969;19:32-6.

14 Breig A, Ekbom K, Greitz T, Kugelberg E. Hydrocephalus due to elongated basilar artery: a new clinicoradiological syndrome. Lancet 1967;i:874-5.
15 Greitz T, Ekbom K, Kugelberg E, Breig A. Occult hydrocephalus due to ectasia of the basijar artery. Acta Radiol [Diag] (Stockh) 1969;9:310-6.

16 Hakim S, Venegas JG, Burton JD. The physics of the cerebral cavity, hydrocephalus and no pressure hydrocept

17 Børgensen SE, Gjerris F. The predictive value of conductance to outflow of CSF in normal pressure hydrocephalus. Brain 1982;105:65-86. 8 Fisher CM. Hydrocephalus as a cause of gait disturbances in the elderly. Neurology 198 2: 1258-63.

19 Grubb RL, Raichle ME, Gado MH, Eichling JO, Hughes CP. Cerebral blood flow ox utilisation and blood volume in dementia. Neurology 1977;27:905-10.

20 Meyer JS, Kitagawa Y, Tanahashi N, et al. Pathogenesis of normal pressure hydrocephalto preliminary observations. Surg Neurol 1985;23:121-33.

21 Mathew NT, Meyer JS, Hartmann A, Ott EO. Abnormal cerebrospinal fluid-blood. How dynamics. Implications in diagnosis, treatment and prognosis in normal pressure hagrocephalus. Arch Neurol 1975;32:657-64.

22 James AE, Strecker EP, Sperber E, Flor WJ, Merz T, Burns B. An alternative pathway of cerebrospinal fluid absorption in communicating hydrocephalus. Radiology 1974;111:143

23 Huckman MS. Normal pressure hydrocephalus: evaluation of diagnostic and prognostic tests. AfNR 1981;2:385-95.

24 Black PMcL. Idiopathic normal pressure hydrocephalus-results of shunting in 62 patien $f$

Neurosurg 1980;52:371-7.
25 Greenberg JO, Shenkin HA, Adams R. Idiopathic normal pressure hydrocephalus-a report 73 patients. I Neurol Neurosurg Psychiatry 1977;40:336-41.

26 Gustafson L, Hagberg B. Recovery in hydrocephalic dementia after shunt operation. $\mathcal{J}$ Newrol Neurosurg Psychiatry 1978;41:940-7.

27 Hughes CP, Siegel BA, Coke WS, et al. Adult idiopathic communicating hydrocephalus withrand without shunting. $\mathcal{F}$ Neurol Neurosurg Psychiatry 1978;41:961-71.

28 Jacobs L, Conti D, Kinkel WR, Manning EJ. "Normal pressure" hydrocephalus. Relationshịpof clinical and radiographic findings to improvement following shunt surgery. JAMA 1976 $510-2$

29 McQuarrie IG, Saint-Louis L, Schrerer PB. Treatment of normal pressure hydrocephalus with low versus medium pressure cerebrospinal fluid shunts. Neurosurgery 1984;15:484-8.

30 Shenkin HA, Greenberg J, Bouzarth WF, Gutterman P, Morales JO. Ventricular shuntingsfor relief of senile symptoms. FAMA 1973;225:1486-9. relief of senile symptoms. $\mathcal{F} A M A$ 1973;225:1486-9.
31 Stein SC, Langfitt TW. Normal pressure hydrocephalus-predicting the results of cerebros ff
fluid shunting. I Neurosurg 1974;41:463-70.

32 LeMay M, New PFJ. Radiological diagnosis of occult normal pressure hydrocephalus. Radiobsgy

jaastad O, Skalpe I, Engeset A. The width of the temporal horn in the differential diagnd tis

between normal pressure hydrocephalus and hydrocephalus ex vacuo. Neurology 196919: 1087-93.

34 Jacobs L, Kinkel W. Computerised axial transverse tomography in normal pressure hydacephalus. Neurology 1976;26:501-7.

35 Yamada F, Fukuda S, Samajima H, Yoshii N, Kudo T. Significance of pathognomonic featun of normal pressure hydrocephalus on computed tomography. Neuroradiology 1978;16:212-3.

36 LeMay M, Hockberg FH. Ventricular difference between hydrostatic hydrocephalus $\mathbb{G}_{\text {nd }}$ hydrocephalus ex vacuo by computed tomography. Neuroradiology 1979;17:191-5.

37 Drayer BP, Rosenbaum AE, Higman HB. Cerebrospinal fluid imaging using serial metriza $\overrightarrow{\eta^{2}}$ de CT cisternography. Neuroradiology 1977;13:7-17.

38 Enzmann DR, Norman D, Price DC, Newton TH. Metrizamide and radionuclide cisternogropphy in communicating hydrocephalus. Radiology 1979;130:681-6.

39 Ostertag CB, Mundinger F. Diagnosis of normal pressure hydrocephalus using CT with $\mathscr{G S F}$ enhancement. Neuroradiology 1978;16:216-9.

40 Bannister R, Gilford E, Kocen R. Isotope encephalography in the diagnosis of dementia d

communicating hydrocephalus. Lancet 1967;ii:1014-7.
41 Heinz ER, Davis DO, Karp HR. Abnormal isotope cisternography in symptomatic of hydrocephalus. Radiology 1970;95:109-20.

42 Patten DH, Benson DF. Diagnosis of normal pressure hydrocephalus by RISA cisternograp Nucl Med 1968:9:457-61.

43 Mahaley MS, Wilkinson RH, Sivalingham J, Friedman H, Tyson W, Goodrich JK. Radionu blood levels during cisternography of patients with normal pressure hydrocephalư or Alzheimer's disease. I Neurosurg 1974;41:471-80.

44 Crockard HA, Hanlon K, Duda EE, Mullan JF. Hydrocephalus as a cause of dementia: evalue by computerised tomography and intracranial pressure monitoring. $f$ Neurol Neuressurg Psychiatry 1977;40:736-40

45 Hartmann A, Alberti E. Differentiation of communicating hydrocephalus and presenile dem by continuous recording of cerebrospinal fluid pressure. $\mathcal{f}$ Neurol Neurosurg Psycheratry 1977;40:630-40.

46 Kostelianetz M, Ingstrup HM. Normal pressure hydrocephalus: correlation between ${ }_{3} \mathrm{CT}$ measurements and cerebrospinal fluid dynamics. Acta Neurochir (Wien) 1985;77:8-13.

47 Wood JH, Bartlett D, James AE, Udvarhelyi GB. Normal pressure hydrocephalus: diagnosif patient selection for shunt surgery. Neurology 1974;24:517-25.

48 Hartmann A, Alberti E, Lange D. Effects of CSF drainage on CBF and CBV in subarachmeid haemorrhage and communicating hydrocephalus. Acta Neurol Scand (Suppl) 1977;56:336-9

49 Lying-Tunell V, Linblad BS, Malmlund HO, Persson B. Cerebral blood flow and metabolic Tate of oxygen, glucose, lactate, pyruvate, ketone bodies and amino acids in patients with nof alal pressure hydrocephalus before and after shunting and in normal subjects. Acta Neurol Sfand pressure hydrocephalus

50 Meyer JS, Kitagawa Y, Tanahashi N, et al. Evaluation of treatment of normal pressire hydrocephalus. $\mathcal{F}$ Neurosurg 1985;62:513-21.

51 Meyer JS, Tachibana H, Hardenberg JP, Dowell RE, Kitagawa Y, Mortel KF. Normal presore hydrocephalus. Influences on cerebral haemodynamic and cerebrospinal fluid pressuf chemical autoregulation. Surg Neurol 1984;21:195-203.

52 Kushner M, Younkin D, Weinberger J, Hurtis H, Goldberg H, Reivich M. Cegeral haemodynamics in the diagnosis of normal pressure hydrocephalus. Neurology 1984;34:968.

53 Luft A, Mamo H, Meric PH, Ponsin JC, Rey A, Seylaz J. Cerebral blood flow measurements in the diagnosis of normal pressure hydrocephalus. 7 Cereb Blood Flow Metab 1983;3 (suppl):56\$6.

54 McGeer PL. Brain imaging in Alzheimer's disease. Br Med Bull 1986;42:24-8.

55 Jagust WJ, Friedland RP, Budinger TF. Positron emission tomography with $\left[{ }^{18} \mathrm{~F}\right]$ Fluorode glucose differentiates normal pressure hydrocephalus from Alzheimer's type dementig $f$ Neurol Neurosurg Psychiatry 1985;48: 1091-6.

56 Gemmel HG, Sharp PF, Evans NTS, Besson JAO, Lyall D, Smith FW. Single photon emi tomography with ${ }^{123} 1$-isopropyl amphetamine in Alzheimer's disease and multi-infarct deetistia. Lancet 1984;ii: 1348 . 